Int. J. Electrochem. Sci., 15 (2020) 10971 - 10978

International Journal of

ELECTROCHEMICAL

SCIENCE

WWW.electrochemsci.org

Short Communication

\title{
Al Thin Films Electrodeposited on Copper in an Aqueous Solution
}

\author{
M. Saitou \\ University of the Ryukyus, Department of Mechanical Systems Engineering, 1 Senbaru Nishihara-cho \\ Okinawa, 903-0213, Japan. \\ E-mail: saitou@tec.u-ryukyu.ac.jp
}

doi: $10.20964 / 2020.11 .52$

Received: 14 July 2020 / Accepted: 9 September 2020 / Published: 30 September 2020

Electrodeposits formed from an aqueous solution by rectangular pulse voltages over a megahertz frequency range were investigated through scanning electron microscopy-energy dispersive X-ray (SEM-EDX) microanalysis and X-ray diffraction (XRD). The SEM-EDX analysis demonstrated that the electrodeposits comprised Al. The current efficiency increased with the cathode potential and tended to become constant, which is in accordance with the phenomenological theory of electrodeposition. The oscillatory change in the current efficiency occurred at resonant frequencies when the cathode potential was equal to the $\mathrm{Al}^{3+}$ potential barrier. The maximum current efficiency was $2.6 \%$ at the resonant frequencies. XRD analysis revealed that the Al thin films had amorphous structures.

Keywords: Al thin film; aqueous solution; potential barrier; cathode potential; amorphous structure

\section{$\underline{\text { FULL TEXT }}$}

(C) 2020 The Authors. Published by ESG (www.electrochemsci.org). This article is an open access article distributed under the terms and conditions of the Creative Commons Attribution license (http://creativecommons.org/licenses/by/4.0/). 